\title{
Vitamin D Enhances Alveolar Development in Antenatal Lipopolysaccharide-Treated Rats through the Suppression of Interferon- $\gamma$ Production
}

\author{
Chengbo $\mathrm{Liu}^{1 \dagger}$, Ze Chen ${ }^{1 \dagger}$, Wen Li', Lisu Huang ${ }^{1,2 *}$ and Yongjun Zhang ${ }^{1,2 *}$ \\ 'Department of Neonatology, Xinhua Hospital, Shanghai Jiaotong University School of Medicine, Shanghai, China, \\ ${ }^{2}$ MOE and Shanghai Key Laboratory of Children's Environmental Health, Shanghai, China
}

\section{OPEN ACCESS}

Edited by:

Diana Boraschi,

Consiglio Nazionale Delle Ricerche

(CNR), Italy

Reviewed by:

Paolo Colombo,

Istituto di biomedicina e di immunologia molecolare Alberto

Monroy (CNR), Italy

Luciana D'Apice,

Consiglio Nazionale Delle Ricerche

(CNR), Italy

*Correspondence:

Lisu Huang

huanglisu@xinhuamed.com.cn;

Yongjun Zhang

zhangyongjun@sjtu.edu.cn

these authors have contributed equally to this work.

Specialty section:

This article was submitted to

Cytokines and Soluble

Mediators in Immunity,

a section of the journal

Frontiers in Immunology

Received: 27 October 2017 Accepted: 15 December 2017

Published: 05 January 2018

Citation:

Liu C, Chen Z, Li W, Huang L and

Zhang Y (2018) Vitamin D Enhances Alveolar Development in Antenatal Lipopolysaccharide-Treated Rats

through the Suppression of Interferon- $\gamma$ Production.

Front. Immunol. 8:1923.

doi: 10.3389/fimmu.2017.01923
Bronchopulmonary dysplasia (BPD) is characterized by the premature arrest of alveolar development. Antenatal exposure to inflammation inhibits lung morphogenesis, thereby increasing the risk for the development of BPD. Here, we investigated whether vitamin D (VitD) enhances alveolar development in antenatal lipopolysaccharide (LPS)-treated rats, which is a model for BPD. We used an established animal model of BPD, and random assignment to the control group, LPS group, or LPS with VitD group. Levels of interferon (IFN)- $\gamma$ and interleukin-4 were detected by real-time polymerase chain reaction (PCR) and enzyme-linked immunosorbent assay. IFN- $\gamma$ producing CD8+ T cells were assessed by flow cytometry, and the methylation status of the VitD-response element (VDRE) was analyzed by bisulfite sequencing PCR. 25-hydroxyvitamin D levels were measured by liquid chromatography tandem mass spectrometry in maternal serum samples collected from 86 pregnant women in a prospective birth cohort enrolled from 2012 to 2013. Our results showed that VitD effectively alleviated the simplification of the lung alveolar structure in BPD rats and suppressed LPS-induced IFN- $\gamma$ expression in the lung and spleen tissues. Further investigation revealed that VitD suppressed IFN- $\gamma$ production in CD8+ T cells. Specifically, VitD increased the methylation percentage of the VDRE in the IFN- $\gamma$-promoter region and suppressed LPS-induced expression of IFN- $\gamma$. Additionally, we observed an association between maternal VitD exposure during pregnancy and neonatal IFN- $\gamma$ levels in a prospective birth cohort, with a trend similar to that observed in the animal model. Our data suggested that supplementation of VitD could suppress IFN- $\gamma$ production, resulting in improved alveolar development in an LPS-induced BPD rat model.

\section{Keywords: bronchopulmonary dysplasia, vitamin $D$, interferon- $\gamma$, methylation, inflammation}

\section{INTRODUCTION}

Bronchopulmonary dysplasia (BPD) has a complex pathogenesis involving multiple insults to the immature lungs that result in varying degrees of alveolar simplification and structural and functional modifications of the arterioles and bronchioles $(1,2)$.

The cellular and molecular mechanisms leading to abnormal lung development in BPD are poorly understood. Triggered in the immature lung by infectious complications, oxygen toxicity, mechanical 
ventilation, a sustained inflammatory response, and extensive remodeling of the extracellular matrix, as well as altered growth factor signaling, characterize the disease $(3,4)$. Several animal models of neonatal lung injury or BPD with an emphasis on postnatal inflammation have been reported (5). Antenatal endotoxins can induce lung inflammation, leading to high neonatal mortality and subsequent arrests in alveolarization in the lungs of infant rats, which is one of the classic animal models of BPD (6). Lung inflammation is recognized as an important risk factor for predisposing the infant to BPD before birth, and cytokines, including interleukin (IL)- $1 \beta$ and interferon (IFN) $-\gamma$, play an important roles in this process $(4,7)$. IFN- $\gamma$ is a proinflammatory cytokine detected in lungs exposed to inflammation and an inducer of effector mechanisms, thereby qualifying it as an early mediator of BPD development $(6,8)$. Recognizing that inflammatory cytokines are involved in lung injury, various investigators explored the potential of inflammatory cytokines as biomarkers for BPD in premature infants (9). Higher serum concentrations of IL-1 $\beta$ and IFN- $\gamma$ and lower concentrations of other cytokines (IL-17) are associated with the development of BPD in preterm babies (10).

Vitamin D (VitD) is involved in many biological processes in addition to its role in the regulation of bone and calcium homeostasis (11). VitD can be metabolized into steroid-hormone metabolites, including 1, 25-dihydroxyvitamin $\mathrm{D}_{3}\left[1,25(\mathrm{OH})_{2} \mathrm{D}_{3}\right]$ (12). Since the discovery of VitD receptors (VDRs) in a variety of cells of the adaptive immune system, such as B and Tymphocytes (13), it has appeared conceivable that VitD might modulate the immune system. Epidemiological studies suggested a relationship between VitD with the incidence of autoimmune diseases $(14,15)$. Additionally, VitD supplementation prevents both the initiation and progression of experimental autoimmune encephalomyelitis and experimental models of multiple sclerosis and rheumatoid arthritis $(16,17)$. Recently, VitD deficiency or insufficiency was associated with respiratory disease in children, as revealed by accumulating epidemiologic evidence (18-20). Furthermore, Fettah et al. (21) reported that lower cord-blood 25(OH)D levels might be associated with increased risk of respiratory distress syndrome in preterm infants. However, the potential mechanisms of VitD-specific regulation of proinflammatory factors remain incompletely understood.

In this study, we reported that VitD supplementation relieved alveolar development impaired by lipopolysaccharide (LPS) by decreasing the production of inflammatory factors, such as IFN- $\gamma$, in a BPD rat model.

\section{MATERIALS AND METHODS}

\section{Experimental Animals}

Timed-pregnancy Sprague-Dawley rats were provided by the Shanghai Laboratory Animal Center (Shanghai, China) and the experimental protocol was approved by the ethics committee of Xinhua Hospital (Shanghai, China).

\section{Animal Model and Study Design}

We used an established animal model of BPD that was described previously $(22,23)$. Briefly, at 16.5 days of gestation (term: 22 days), pregnant rats were prepared for receiving intra-amniotic injections. The pregnant rats were randomly assigned to the saline control group, LPS group, or LPS with VitD group. The saline control group received $5 \mu \mathrm{L}$ of normal saline per amniotic sac, the LPS group received $1 \mu \mathrm{g}$ of LPS (Escherichia coli 055:B5; Sigma-Aldrich, St. Louis, MO, USA) diluted to $5 \mu \mathrm{L}$ with normal saline per amniotic sac, and the LPS with VitD group received $1 \mu \mathrm{g}$ of LPS and $5 \mathrm{pg}$ of $1,25(\mathrm{OH})_{2} \mathrm{D}_{3}$ (Sigma-Aldrich) diluted to $5 \mu \mathrm{L}$ with normal saline per amniotic sac. The day when the pups were born was counted as postnatal day 0 (P0). The pups from the LPS with VitD group were injected with $1,25(\mathrm{OH})_{2} \mathrm{D}_{3}$ (1 ng/g) according to their weight daily from P0 to P7, whereas pups from the saline control and LPS groups were injected with normal saline at the same volume.

\section{Lung and Spleen Processing}

At P1, P3, and P7, 20-30 newborn rats from each model or control group were anesthetized by intraperitoneal injection of $5 \%$ chloral hydrate, and whole lungs and spleen were aseptically collected by a chest- and abdomen-opening procedure. The right bronchus and trachea were ligated, and spleen tissues were decollated from the great bend of the stomach. The pups then received intratracheal instillation of buffered formaldehyde [4\% paraformaldehyde solubilized in phosphate-buffered saline (PBS); $\mathrm{pH} 7.4]$ at a pressure of $20 \mathrm{~cm} \mathrm{H}_{2} \mathrm{O}$ for $20 \mathrm{~min}$. For histological analysis, the left upper lobes were formaldehyde-fixed and paraffin-embedded. Serial 5-mm thick sections were stained with hematoxylin and eosin (H\&E). For IFN- $\gamma$ and IL-4 measurements, the right lung lobes without perfusion and spleen tissues were excised, frozen in liquid nitrogen, and stored at $-80^{\circ} \mathrm{C}$.

\section{Lung Morphometry}

Three pups were selected from each group, and five random non-overlapping fields in one distal lung section per pup were utilized for morphometric examinations. The terminal airspace, secondary septa, and myofibroblasts in each field were manually counted. The mean linear intercept (MLI) was determined by superimposing a predetermined grid with set randomly placed lines totaling $1 \mathrm{~mm}$ in actual length onto the image and counting the number of times the lines cross an air-tissue interface. The actual MLI was calculated as the inverse of the number of air-tissue interfaces per millimeter $(1,000 \mu \mathrm{m})$ and was used to estimate the mean distal airspace size.

\section{IFN- $\gamma$ and IL-4 Measurements by Real- time Polymerase Chain Reaction (PCR)}

Total mRNA was extracted from five to seven right upper lung lobe and spleen tissues from all groups at P1, P3, and P7. The samples were subjected to reverse transcription and real-time PCR (Life Technologies, Carlsbad, CA, USA) according to manufacturer instructions. Real-time PCR was performed using SYBR Green PCR master mix (Applied Biosystems), and data were collected and quantitatively analyzed on an ABI Prism 7500 sequence detection system (Applied Biosystems). All primers were obtained as amplimer sets from Sangon Biotech (Shanghai, China). The following primers were used: $\beta$-actin (forward, 5'-GGAAATCGTGCGTGACATTA-3'; reverse, 5'-AGGAAGG 
AAGGCTGGAAGAG-3'); IFN- $\gamma$ (forward, 5' -AGGTGAACAA CCCACAGAT-3'; reverse, $5^{\prime}$-CTTCTTATTGGCACACTCTC TAC-3'); and IL-4 (forward, 5' -ACAAGGAACACCACGGAG AA-3'; reverse, 5'-CAGACCGCTGA- CACCTCTACA-3'). Model data were standardized to $\beta$-actin.

\section{IFN- $\gamma$ and IL-4 Enzyme-Linked Immunosorbent Assay (ELISA)}

The production of IFN- $\gamma$ and IL- 4 in the five to seven right lower lung lobe and spleen tissues from each group at P1, P3, and P7 were assessed using the IFN- $\gamma$ and IL-4 ELISA kit (R\&D Systems, Minneapolis, MN, USA) according to manufacturer instructions. Tissues homogenates were prepared in $1 \times$ PBS and frozen at $-80^{\circ} \mathrm{C}$. Homogenates were subjected to two cycles of thawing and freezing, centrifuged, and supernatants were collected for ELISA measurement. Total protein in tissues was determined using the Pierce BCA protein assay kit (Beyotime Biotechnology, Shanghai, China) and used for normalization purposes.

\section{Bisulfite Sequencing PCR}

The genomic DNA from four lung tissues collected at P3 from each group was extracted using a blood/cell/tissue genomic DNA extraction kit (Tiangen Biotech, Beijing, China). After elution with preheated $70^{\circ} \mathrm{C}$ sterile water, the DNA was collected. Thereafter, DNA specimens were treated with a DNA methylation kit (Millipore, Billerica, MA, USA) and amplified. PCR amplification conditions were $95^{\circ} \mathrm{C}$ for $5 \mathrm{~min}, 95^{\circ} \mathrm{C}$ for $10 \mathrm{~s}, 50^{\circ} \mathrm{C}$ for $20 \mathrm{~s}, 72^{\circ} \mathrm{C}$ for $30 \mathrm{~s}$ for a total of 35 cycles, followed by one cycle at $4^{\circ} \mathrm{C}$ for $5 \mathrm{~min}$. PCR primers were designed using MethPrimer software (http:// www.urogene.org/methprimer/) and included forward primer (5'-AATAAATGTTTATTGTGTTGTATTTTG- ${ }^{\prime}$ ) and reverse primer (5'-AA-CTCCTATATTAAATCAAAAAATCC- $\left.3^{\prime}\right)$. The amplicons were confirmed by agarose gel electrophoresis and sequenced using a BiQ Analyzer (24).

\section{Preparation, Culture, and Treatments of Bone Marrow-Derived Macrophages (BMDMs)}

Bone marrow-derived macrophages were isolated from the marrow of femurs and tibias from 4-week-old male rats $(100-150 \mathrm{~g})$. Cells were then differentiated into BMDMs in Roswell Park Memorial Institute medium containing $10 \mathrm{ng} / \mathrm{mL}$ recombinant M-CSF (Sigma-Aldrich), 10\% fetal bovine serum (Gibco, Paisley, UK), and streptomycin/penicillin (Gibco). Cellculture population consisted of nearly $80 \%$ BMDMs at 7 days after seeding. The cells were harvested, washed with complete media, and plated in 6-well plates with or without 5-Aza-2'deoxycytidine (5-aZac; $10 \mu \mathrm{mol} / \mathrm{L}$; Abcam, Cambridge, UK) for $48 \mathrm{~h}$. The cells without 5 -aZac were stimulated with PBS, LPS $(1 \mu \mathrm{g} / \mathrm{mL})$, or LPS $(1 \mu \mathrm{g} / \mathrm{mL})+1,25(\mathrm{OH})_{2} \mathrm{D}_{3}(100 \mathrm{pg} / \mathrm{mL})$ for $12 \mathrm{~h}$, respectively, whereas cells with 5 -aZac were stimulated with LPS $(1 \mu \mathrm{g} / \mathrm{mL})+1,25(\mathrm{OH})_{2} \mathrm{D}_{3}(100 \mathrm{pg} / \mathrm{mL})$ for $12 \mathrm{~h}$. After storage in liquid nitrogen, the cells and supernatant of five samples from four groups were transferred to a $-80^{\circ} \mathrm{C}$ freezer, respectively, and then subsequently used for real-time PCR and ELISA analyses.

\section{Flow Cytometry}

Spleen tissues from three pups from each group were collected at P15, and single-cell suspensions were prepared by homogenization through a $75-\mu \mathrm{m}$ cell strainer. Red blood cells were lysed (RBC lysing buffer; Beyotime Biotechnologies), whereas splenocytes were washed and resuspended in FACS buffer (Hank's Balanced Salt Solution supplemented with $2 \%$ fetal calf serum). The cells were characterized by surface staining with anti-rat antibodies against CD3 and CD8. For intracellular staining, surface-stained cells were washed in FACS buffer and permeabilized with IC fixation buffer/permeabilization buffer for $30 \mathrm{~min}$, followed by washing and staining in FACS buffer with anti-rat antibodies against IFN- $\gamma$ for $30 \mathrm{~min}$. All antibodies were purchased from eBioscience (San Diego, CA, USA), and all flow-cytometry experiments were performed using LSR II (BD Systems, UK).

\section{Cohort Study Design and Participants}

This was a prospective birth cohort study that recruited 1,071 maternal-child pairs between 2012 and 2013 at Xinhua Hospital and the International Peace Maternity and Child Hospital, two large tertiary hospitals in Shanghai, China. Prior to delivery, written informed consent was obtained from the mothers and trained nurses conducted face-to-face interviews $(25,26)$. At birth, study nurses collected anthropometric details and umbilical-cord blood from the newborns, when available. Ethics approval was obtained by the Ethics Committees of both Xinhua Hospital and the International Maternal and Children Care Hospital. Because the mode of delivery might affect the inflammation status of the neonate, we only included data obtained from cesarean sections on maternal request. Mothers diagnosed with gestational complications were excluded. In the final analysis, 86 mother-infant pairs were included.

\section{Measurement of VitD, INF- $\gamma$, and IL-4 in Maternal and Umbilical Cord Blood}

We used liquid chromatography tandem mass spectrometry (LC-MS/MS) to detect serum $25(\mathrm{OH}) \mathrm{D}$ according to the procedure reported by our previous study (25). INF- $\gamma$ and IL- 4 were measured using an ELISA kit (LDN GmbH \& Co., Nordhorn, Germany) according to manufacturer protocol.

\section{Statistical Analysis}

Data are presented as the mean $\pm \mathrm{SD}$. The variance test was equal. The Student's $t$-test and one-way ANOVA analysis were performed using SPSS 18.0 software (SPSS, Inc., Chicago, IL, USA) to analyze the statistical significance of the comparisons. The Student-Newman-Keuls method was used to compare differences of IFN- $\gamma$ and IL-4 between VitD groups. Statistical significance was defined as a $P<0.05$. VitD levels $<20 \mathrm{ng} / \mathrm{mL}$ were generally considered as deficiencies. We stratified all samples into three groups $(<20,20-30$, and $\geq 30 \mathrm{ng} / \mathrm{mL})$. The difference in VitD level between cord blood and that obtained mid-trimester was calculated as the change in VitD as was stratified into three groups $(<0,0-10$, and $\geq 10 \mathrm{ng} / \mathrm{mL})$. 


\section{RESULTS}

\section{VitD Treatment Improves Alveolar Development in Antenatal LPS- treated Rats}

First, we tested whether VitD could rescue alveolar development following LPS exposure. No fetal death occurred in the control group, and almost all rats survived until the end of the experiment. The survival rates of the pups in the LPS group and the pups in the LPS with VitD group were similar (80 and $83.5 \%$, respectively). The lung structures of the pups in the LPS group had typical characteristics of alveolar simplification, as indicated by enlarged alveoli with a decreased terminal airspace, decreased secondary septa, and an increased MLI.

We then examined the effect of VitD treatment on LPS-induced alveolar simplification (Figure 1A). Pups receiving LPS and VitD co-treatment showed a significantly increased terminal airspace and significantly reduced MLI at P1, P3, and P7 as compared with pups receiving LPS treatment alone $(P<0.05)$. In terms of the secondary septa, the difference between P1 and P7 was not significant in the LPS groups with or without VitD (Figure 1B). These results suggested that VitD effectively alleviated lung alveolar structure simplification induced by LPS.

\section{IFN- $\gamma$ mRNA and Protein Levels in Antenatal LPS-Treated Rats Are Regulated by VitD}

We then investigated the effects of VitD treatment on the regulation of inflammation. VitD suppressed LPS-induced IFN- $\gamma$ mRNA and protein expression in the lung at P1, P3, and P7 $(P<0.05)$ (Figure 2A). Additionally, IFN- $\gamma$ mRNA and protein expression in the spleen were similarly significantly decreased
A

P1
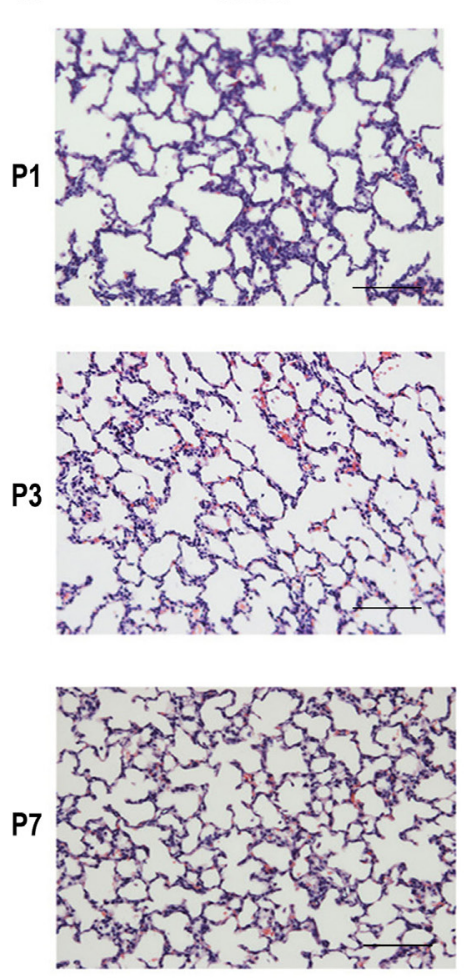

B

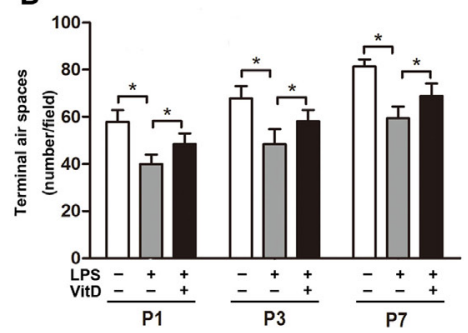

LPS
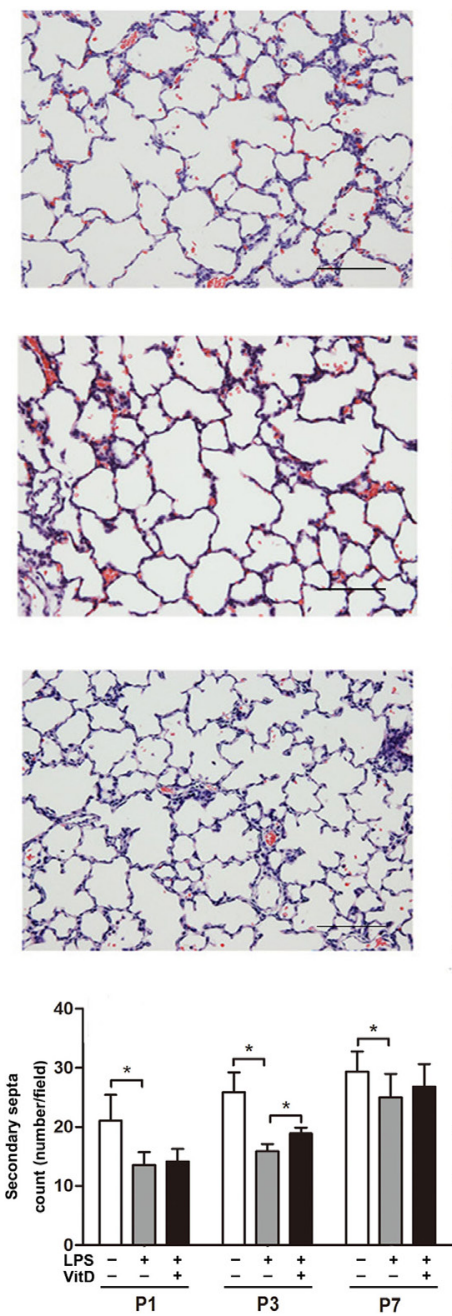

LPS+VitD
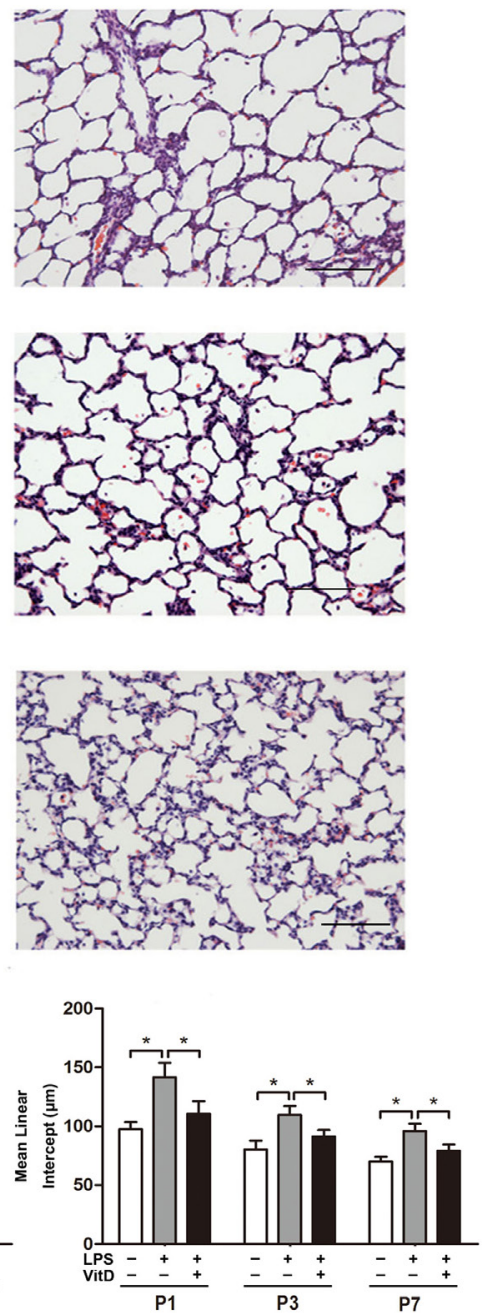

FIGURE 1 | Vitamin D treatment improves lung structure in antenatal lipopolysaccharide (LPS)-treated rats. (A) Representative lung sections stained with H\&E. (B) Quantification of the terminal airspace, secondary septa, and mean linear intercept. Bars, $200 \mu \mathrm{m}$. Data represent the mean \pm SD. ${ }^{*} p<0.05$ ( $n=3$ pups per group, with at least five replicates). 

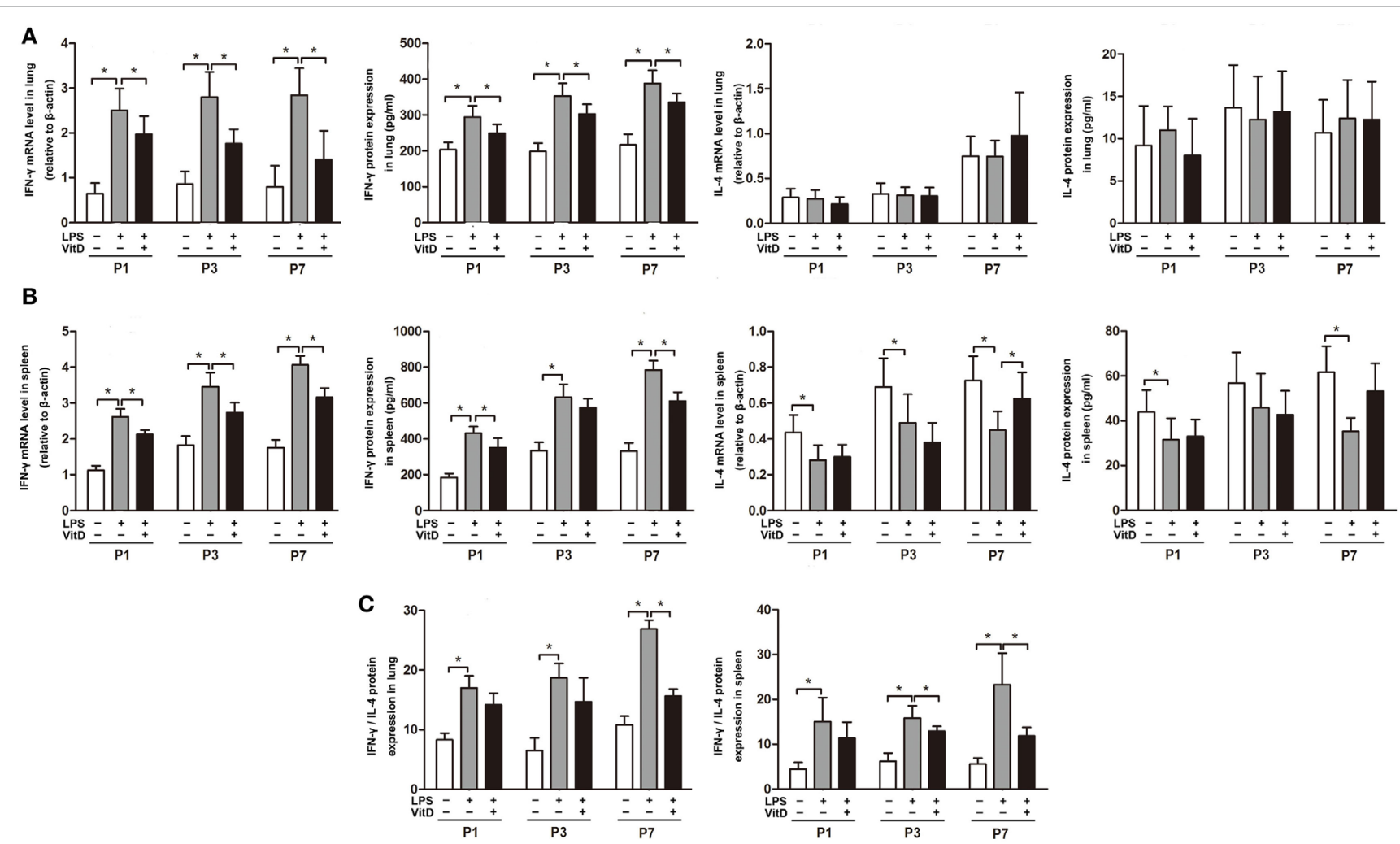

FIGURE 2 | Interferon (IFN- $\gamma$ ) mRNA and protein levels in antenatal lipopolysaccharide (LPS)-treated rats are regulated by VitD. (A) IFN- $\gamma$ and interleukin (IL)-4 mRNA and protein levels in rat lung tissue and (B) spleen. (C) IFN- $\gamma / \mathrm{IL}-4$ ratio in the lung and spleen. Data represent the mean $\pm \mathrm{SD}$. ${ }^{*} p<0.05(n=5-7$ pups for each group; experiments were repeated five times for each data point).

by VitD at P1 and P7 as compared with pups in the LPS group $(P<0.05)$ (Figure 2B), whereas levels of IL-4 in lung and spleen tissues were insuscepti ble to VitD. We also contrasted the IFN- $\gamma /$ IL-4 protein-expression ratio in the lung and spleen, finding that antenatal LPS injection increased the IFN- $\gamma / \mathrm{IL}-4$ ratio in lung and spleen tissues, whereas VitD treatment significantly decreased this ratio in lung tissue at P7 and in spleen tissue at P3 and P7 (Figure 2C).

\section{VitD Supplementation Changes the Percentage of IFN- $\gamma$-Producing CD8+ T Cells in the Spleen of BPD Rats}

Our attempt to examine whether VitD treatment impacted the numbers of CD4+ $\mathrm{T}$ cells in lung and spleen tissues revealed that only a tiny minority of CD4+ T cells were detected in these tissues. Because IFN- $\gamma$ can also be expressed in CD8+ T cells, we investigated whether VitD treatment was associated with a reduction in the numbers of IFN- $\gamma$-producing CD8+ T cells. In lung tissues, CD8+ T cells were not randomly dispersed, allowing their accurate detection; however, comparison of the number of IFN- $\gamma$-producing CD8+ T cells in spleen tissue from BPD rats in the LPS and LPS with VitD groups at P15 revealed that the VitD treatment led to a significant decrease in the frequency of IFN- $\gamma$-producing CD8+ T cells in the spleen, as indicated by a reduction in the potential for IFN- $\gamma$ production (Figure $3 \mathrm{~A}, \mathrm{~B}$ ).

\section{VitD Treatment Alters the Methylation Status of the VitD-Response Element (VDRE) in the IFN- $\gamma$-Promoter Region}

We then analyzed the relationship between the percentage of methylation of the VDRE in the IFN- $\gamma$-promoter region combined with those of the VDR and VitD levels in the lung tissue of pups from all of the groups at P3. There are six sites in the IFN- $\gamma$-promoter region $(-108$ to $+64 \mathrm{bp})$ that were combined with VDR. We observed that lung-tissue samples of rats from all groups showed highly methylated and that VitD treatment significantly increased the methylation percentage of the VDRE in the IFN- $\gamma$-promoter region as compared with LPS treatment $(P<0.05)$ (Figure 4A). Furthermore, the regulation of IFN- $\gamma$ expression by VitD treatment disappeared following administration of the methylation inhibitor 5-aZac (Figure 4B).

\section{VitD Regulates IFN- $\gamma$ and IL-4 Levels in Cord Blood}

To confirm our findings, we assessed correlations between maternal VitD exposure and IFN- $\gamma$ and IL-4 levels in newborns. The median maternal serum VitD concentration at 24-28 gestational weeks was $20.1 \mathrm{ng} / \mathrm{mL}(10.2-26.8 \mathrm{ng} / \mathrm{mL})$. Additionally, neonatal IFN- $\gamma$ levels were significantly lower in the group of pregnant 


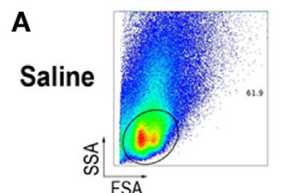

कSA

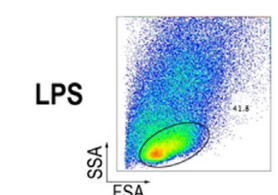

FSA

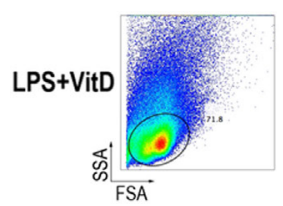

ơ!
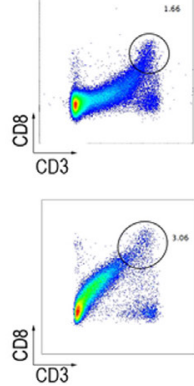

$\mathrm{CD} 3$

$\mathrm{O}$

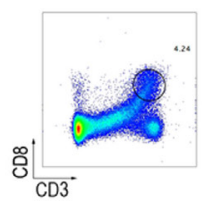

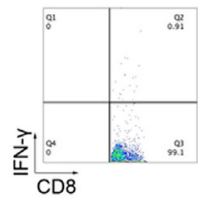

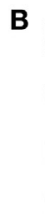

B
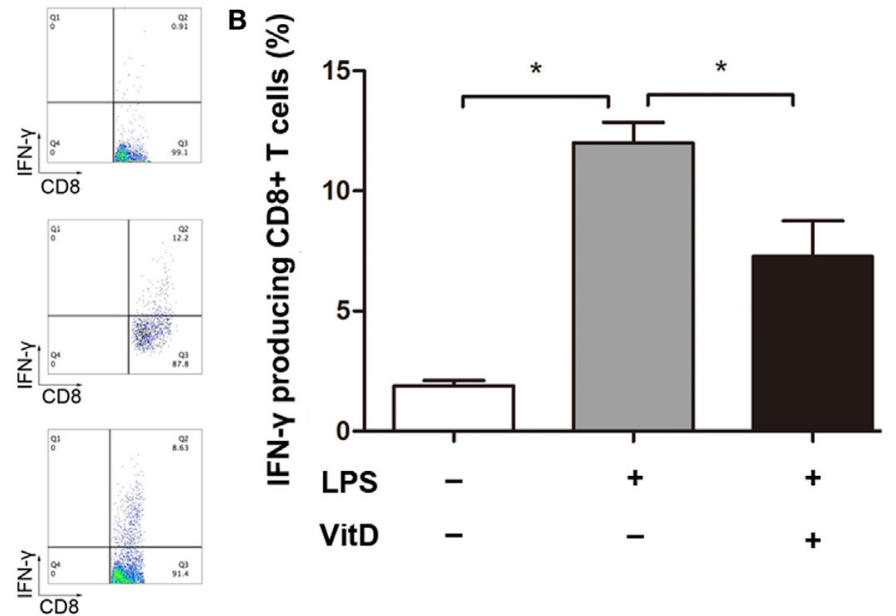

FIGURE 3 | VitD supplementation changes the percentage of interferon (IFN)- $\boldsymbol{\gamma}$-producing CD8+ T cells in the spleen of bronchopulmonary dysplasia rats. (A) A representative flow plot of IFN- $\gamma$-producing CD8+ T cells in each group. (B) Quantitative analysis of the percentage of IFN- $\gamma$ intracellular-stained CD8+ T cells. Data represent the mean \pm SD. ${ }^{\star} p<0.05$ ( $n=3$ pups for each group; each experiment was repeated at least four times).
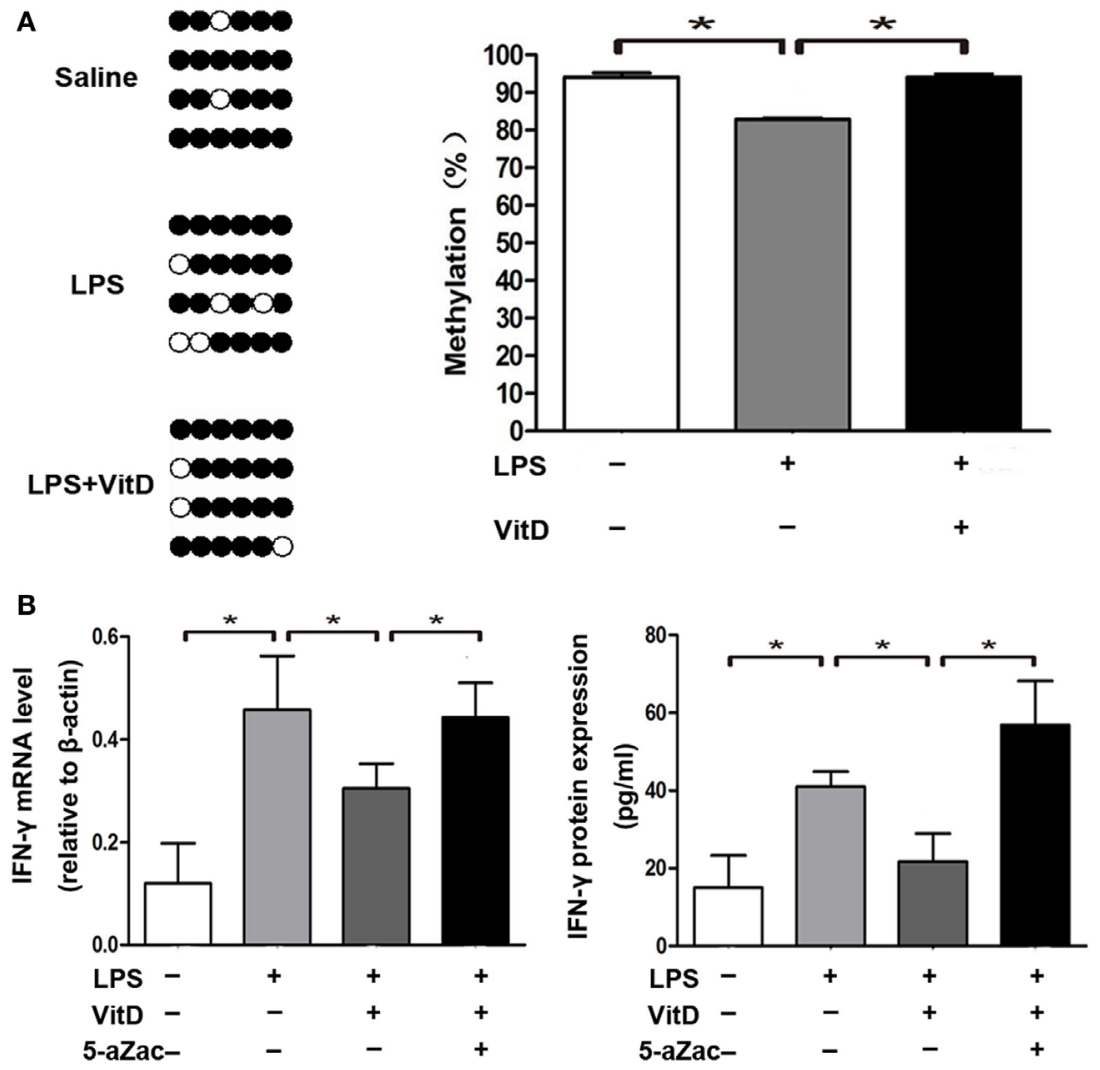

FIGURE 4 | Vitamin D treatment alters the methylation status of the VitD-response element in the interferon (IFN)- $\boldsymbol{\gamma}$-promoter region. (A) DNA methylation in the IFN- $\gamma$-promoter region in lung tissue from all groups. Results showing representative methylation and quantification of the proportion of methylation in the three experimental groups are shown ( $n=4$ pups at P3 for every group). (B) IFN- $\gamma$ mRNA and protein levels in macrophages after 48-h treatment with the inhibitor 5-aZac $(10 \mu \mathrm{mol} / \mathrm{L})(n=5$ samples from the four groups; each experiment was repeated four times). Data represent the mean $\pm \mathrm{SD}$. * $p<0.05$.

mothers with VitD concentrations $\geq 30 \mathrm{ng} / \mathrm{mL}$, whereas IL-4 levels were significantly higher in this group (Figure 5A). Moreover, increased VitD intake during the last trimester resulted in lower neonatal INF- $\gamma$ levels and INF- $\gamma / \mathrm{IL}-4$ ratios in cord blood (Figure 5B). This trend was similar to those observed in the animal model. 

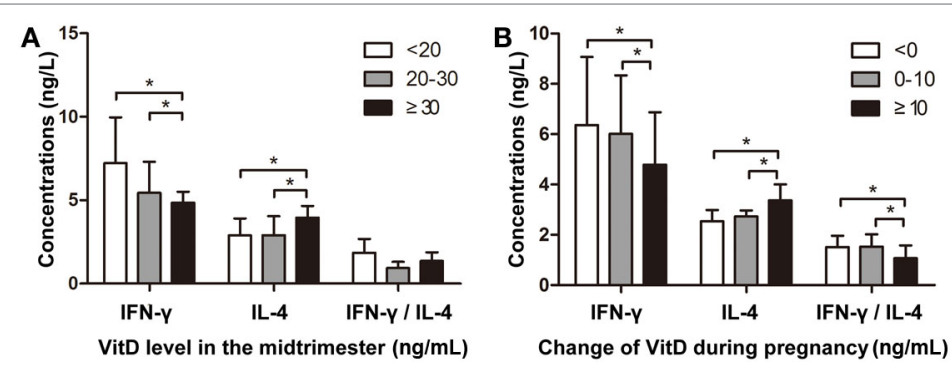

FIGURE 5 | Vitamin D regulates interferon (IFN)- $\gamma$ and interleukin (IL)-4 levels in cord blood. (A) The association between VitD concentration during the mid-trimester and IFN- $\gamma$ and IL-4 levels in cord blood. The $Y$-axis represents IFN- $\gamma$ and IL-4 concentrations and the IFN- $\gamma / \mathrm{IL}-4$ ratio $\mathrm{VitD}$ levels: $<20$ ng/mL $(n=36) ; 20-30$ ng/mL $(n=32) ; \geq 30 \mathrm{ng} / \mathrm{mL}(n=18)]$. (B) The association between altered VitD supplementation during pregnancy and IFN- $\gamma$ and IL-4 levels in cord blood. The $Y$-axis represents IFN- $\gamma$ and IL-4 concentrations and IFN- $\gamma / \mathrm{IL}-4$ ratio [changes in VitD concentration: $<0 \mathrm{ng} / \mathrm{mL}(n=33) ; 0-10 \mathrm{ng} / \mathrm{mL}(n=29) ; \geq 10 \mathrm{ng} / \mathrm{mL}(n=24)$ ]. Data represent the mean $\pm \mathrm{SD}$. ${ }^{*} p<0.05$.

\section{DISCUSSION}

Bronchopulmonary dysplasia pathogenesis is multifactorial; however, all of its triggers cause pulmonary inflammation and might, therefore, inhibit lung morphogenesis. Inflammation is generally believed to be a primary mediator of injury associated with BPD pathogenesis $(27,28)$. The central role of perinatal inflammation and its possible consequence of fetal inflammatory response syndrome led the BPD Group of the American Academy of Pediatrics to make the identification of anti-inflammatory agents associated with the development of perinatal inflammation a research priority (28).

Vitamin D supports an emerging hypothesis that early maternal VitD deficiency might contribute to a high risk for subsequent asthma and BPD during infancy $(18,29,30)$. Previous studies also suggest that VitD treatment might be protective against respiratory distress syndrome in preterm neonates (12). In our study, we verified that sustainable VitD supplementation during the fetal and neonatal periods could indeed alleviate morphological changes of the lung in LPS-induced BPD animal models.

Interferon $-\gamma$ induced by LPS is mainly involved in cellular immunity and reportedly plays an important role in the development of BPD (31). In the current study, we observed that IFN- $\gamma$ expression was decreased along with VitD supplementation. Evidence suggests that VitD might stimulate $\mathrm{T}$ cell differentiation and suppress inflammatory responses to environmental exposures (32). This results in a variety of important biological activities, as not only is IFN- $\gamma$ a vital initiator of inflammation by LPS, it also promotes T helper (Th) 1 cell responses and results in Th1 and Th2 responses to environmental exposure, thereby conferring antimicrobial activity $(32,33)$. Th1 cells secrete proinflammatory factors (primarily IFN- $\gamma$ ) and are mainly involved in cellular immunity. Whereas Th2 cells produce antiinflammatory factors (primarily IL-4) and are associated with humoral immunity. The levels of IFN- $\gamma$ and IL- 4 can indirectly reflect situations associated with Th1/Th2 shifting and the balance between anti-inflammatory and proinflammatory responses (34). Here, we also detected changes in IL-4 levels and compared IFN- $\gamma / \mathrm{IL}-4$ ratios in the treatment groups. These results showed that VitD mainly decreased the IFN- $\gamma$ expression, thereby promoting an imbalance of IFN- $\gamma$ and IL- 4 in BPD rats, leading to suppression of local inflammation in lung tissue and of systemic inflammation. Neonatal $\mathrm{T}$ cell responses were historically thought to be deficient due to immaturity (8), which might explain why CD4+ T cells and portions of CD8+ T cells were undetectable in our research. Our data suggested that VitD treatment was associated with reductions in IFN- $\gamma$-producing $\mathrm{CD} 8+\mathrm{T}$ cells in spleen tissue. Moreover, these results indicated a potential mechanism associated with VitD-related improvement of lung structure in LPS-induced BPD rats through its regulation of IFN- $\gamma$ expression.

However, the underlying mechanisms associated with the regulation of IFN- $\gamma$ expression by VitD remain unclear. VitD can regulate gene expression and exert widespread immunomodulatory effects (35-37). In the present study, we explored associations between VitD and IFN- $\gamma$ expression by analyzing the relationship between methylation percentages in the VDRE located in the IFN- $\gamma$-promoter region. As we hypothesized, VitD increased the percentage of methylation of VDRE in the IFN- $\boldsymbol{\gamma}$-promoter region to a greater extent than that of LPS treatment alone. Recent studies showed that DNA methylation, a key epigenetic mechanism, is altered in children exposed to air pollutants and environmental tobacco smoke early in life (38). An example of this is the intrauterine or postpartum environment, which causes DNA methylation and makes infants susceptible to chronic obstructive pulmonary disease, asthma, and other respiratory system diseases (39). Previous studies indicated that epigenetic mechanisms play a significant role in the inflammatory process, regardless of whether it occurs locally or systemically. Additionally, altered DNA methylation in lung tissues plays a major role in LPS-induced lung injury (40). Interestingly, $1,25(\mathrm{OH})_{2} \mathrm{D}_{3}$ can enter cells and bind to receptors, during which the resulting complex heterodimerizes with the retinoid $\mathrm{X}$ receptor and binds to the VDRE in the promoters of target genes of pro-inflammation factors, thereby affecting their transcription (41). The VDR protein physically interacts with co-activator and co-repressor proteins, which, in turn, come into contact with chromatin modifiers, such as histone acetyltransferases and histone methyltransferases, and chromatin remodelers (11). Based on these findings, we assessed the six CpG sites in the VDRE 
of the IFN- $\gamma$-promoter region, which are mainly regulated by VitD. However, we acknowledge the possibility of missing other $\mathrm{CpG}$ sites in the promoter region; therefore, further studies are needs to understand other molecular mechanisms underlying epigenetic regulation of IFN- $\gamma$ expression by VitD. To verify our hypothesis concerning the regulation of methylation by VitD, we observed that administration of the nonspecific methylation inhibitor 5-aZac significantly blocked VitD regulation of IFN- $\gamma$ expression in rat BMDMs. These results suggested that VitD mediated the DNA methylation associated with downregulation of IFN- $\gamma$ levels during LPS-induced BPD.

Vitamin D is hypothesized as being important to immune and inflammatory responses (42); however, it is unknown whether VitD suppresses proinflammatory cytokine activation in vivo, particularly in the context of fetal immune ontogeny. In this study, we found that neonatal INF- $\gamma$ levels were significantly lower in the group of mothers with VitD concentrations $\geq 30 \mathrm{ng} / \mathrm{mL}$ during the mid-trimester, whereas IL-4 levels were significantly higher in this group. These results might suggest that the higher VitD concentration was associated with altered INF- $\gamma$ levels to suppress inflammation. Additionally, increased intake of VitD during the last trimester resulted in lower INF- $\gamma$ levels and INF- $\gamma$ / IL-4 ratios in cord blood, a trend similar to that observed in the animal model. These findings also supported our hypothesis that VitD supplementation could relieve inflammatory injury through the suppression of IFN- $\gamma$ production. Furthermore, although maternal VitD exposure during pregnancy was associated with neonatal IFN- $\gamma$ levels, additional intervention studies are necessary to prove causality.

In summary, our results established a new molecular mechanism pertaining to the VitD-related improvement of lung morphogenesis following intrauterine inflammation. Our findings showed that VitD alleviated morphological changes of the lung in LPS-induced BPD rats. Most importantly, we demonstrated

\section{REFERENCES}

1. Hadchouel A, Franco-Montoya ML, Delacourt C. Altered lung development in bronchopulmonary dysplasia. Birth Defects Res A Clin Mol Teratol (2014) 100(3):158-67. doi:10.1002/bdra.23237

2. Niedermaier S, Hilgendorff A. Bronchopulmonary dysplasia - an overview about pathophysiologic concepts. Mol Cell Pediatr (2015) 2(1):2. doi:10.1186/ s40348-015-0013-7

3. Meiners S, Hilgendorff A. Early injury of the neonatal lung contributes to premature lung aging: a hypothesis. Mol Cell Pediatr (2016) 3(1):24. doi:10.1186/ s40348-016-0052-8

4. Shahzad T, Radajewski S, Chao CM, Bellusci S, Ehrhardt H. Pathogenesis of bronchopulmonary dysplasia: when inflammation meets organ development. Mol Cell Pediatr (2016) 3(1):23. doi:10.1186/s40348-016-0051-9

5. Bhandari V. Postnatal inflammation in the pathogenesis of bronchopulmonary dysplasia. Birth Defects Res A Clin Mol Teratol (2014) 100(3):189-201. doi:10.1002/bdra.23220

6. Choi CW, Lee J, Oh JY, Lee SH, Lee HJ, Kim BI. Protective effect of chorioamnionitis on the development of bronchopulmonary dysplasia triggered by postnatal systemic inflammation in neonatal rats. Pediatr Res (2016) 79(2):287-94. doi:10.1038/pr.2015.224

7. Jobe AH. Mechanisms of lung injury and bronchopulmonary dysplasia. Am J Perinatol (2016) 33(11):1076-8. doi:10.1055/s-0036-1586107

8. Jackson CM, Wells CB, Tabangin ME, Meinzen-Derr J, Jobe AH, Chougnet CA. Pro-inflammatory immune responses in leukocytes of premature infants that VitD supplementation suppressed IFN- $\gamma$ production and inhibited the inflammatory response.

\section{ETHICS STATEMENT}

Timed-pregnancy Sprague-Dawley rats were provided by the Shanghai Laboratory Animal Center and the experimental protocol was approved by the ethics committee of Xinhua Hospital. Ethics approval of the prospective birth cohort study was obtained by the Ethics Committees of both Xinhua Hospital and the International Maternal and Children Care Hospital.

\section{AUTHOR CONTRIBUTIONS}

All authors contributed to the intellectual content of the manuscript and approved the manuscript version submitted for publication. CL, ZC, WL, and LH performed the experiments; CL, $\mathrm{ZC}$, and $\mathrm{LH}$ analyzed the data and prepared the figures; CL, ZC, $\mathrm{LH}$, and YZ interpreted the experimental results; CL drafted the manuscript; $\mathrm{YZ}$ was responsible for the conception and design of the research and approved the final version of the manuscript; LH and $\mathrm{YZ}$ edited and revised the manuscript.

\section{ACKNOWLEDGMENTS}

We thank Professor Lei Shen, Department of Immunology, Shanghai Jiaotong University School of Medicine, for technical guidance related to flow cytometry.

\section{FUNDING}

This work was supported by the National Natural Science Foundation of China (grant No.81741084 and No.81470201 to YZ and No.81402686 to LH).

exposed to maternal chorioamnionitis or funisitis. Pediatr Res (2017) 81(2):384-90. doi:10.1038/pr.2016.232

9. Lal CV, Ambalavanan N. Biomarkers, early diagnosis, and clinical predictors of bronchopulmonary dysplasia. Clin Perinatol (2015) 42(4):739-54. doi:10.1016/j.clp.2015.08.004

10. Ambalavanan N, Carlo WA, D’Angio CT, McDonald SA, Das A, Schendel D, et al. Cytokines associated with bronchopulmonary dysplasia or death in extremely low birth weight infants. Pediatrics (2009) 123(4):1132-41. doi:10.1542/peds.2008-0526

11. Fetahu IS, Hobaus J, Kallay E. Vitamin D and the epigenome. Front Physiol (2014) 5:164. doi:10.3389/fphys.2014.00164

12. McCarthy RA, McKenna MJ, Oyefeso O, Uduma O, Murray BF, Brady JJ, et al. Vitamin D nutritional status in preterm infants and response to supplementation. Br J Nutr (2013) 110(1):156-63. doi:10.1017/S0007114512004722

13. Provvedini DM, Tsoukas CD, Deftos LJ, Manolagas SC. 1,25dihydroxyvitamin D3 receptors in human leukocytes. Science (1983) 221(4616):1181-3. doi:10.1126/science.6310748

14. Hyppönen E, Läärä E, Reunanen A, Järvelin M-R, Virtanen SM. Intake of vitamin D and risk of type 1 diabetes: a birth-cohort study. Lancet (2001) 358(9292):1500-3. doi:10.1016/s0140-6736(01)06580-1

15. Aranow C, Kamen DL, Dall'Era M, Massarotti EM, Mackay MC, Koumpouras F, et al. Randomized, double-blind, placebo-controlled trial of the effect of vitamin D3 on the interferon signature in patients with systemic lupus erythematosus. Arthritis Rheumatol (2015) 67(7):1848-57. doi:10.1002/ art.39108 
16. Bora S, Cantorna MT. The role of UVR and vitamin D on T cells and inflammatory bowel disease. Photochem Photobiol Sci (2017) 16(3):347-53. doi:10.1039/c6pp00266h

17. Dankers W, Colin EM, van Hamburg JP, Lubberts E. Vitamin D in autoimmunity: molecular mechanisms and therapeutic potential. Front Immunol (2016) 7:697. doi:10.3389/fimmu.2016.00697

18. Brehm JM, Acosta-Perez E, Klei L, Roeder K, Barmada M, Boutaoui N, et al. Vitamin D insufficiency and severe asthma exacerbations in Puerto Rican children. Am J Respir Crit Care Med (2012) 186(2):140-6. doi:10.1164/ rccm.201203-0431OC

19. Brehm JM, Celedon JC, Soto-Quiros ME, Avila L, Hunninghake GM, Forno E, et al. Serum vitamin D levels and markers of severity of childhood asthma in Costa Rica. Am J Respir Crit Care Med (2009) 179(9):765-71. doi:10.1164/rccm.200808-1361OC

20. Misra M, Pacaud D, Petryk A, Collett-Solberg PF, Kappy M. Vitamin D deficiency in children and its management: review of current knowledge and recommendations. Pediatrics (2008) 122(2):398-417. doi:10.1542/peds. 2007-1894

21. Fettah ND, Zenciroglu A, Dilli D, Beken S, Okumus N. Is higher 25hydroxyvitamin D level preventive for respiratory distress syndrome in preterm infants? Am J Perinatol (2015) 32(3):247-50. doi:10.1055/s-0034-1383849

22. Li J, Li Y, He H, Liu C, Li W, Xie L, et al. Csk/Src/EGFR signaling regulates migration of myofibroblasts and alveolarization. Am J Physiol Lung Cell Mol Physiol (2016) 310(6):L562-71. doi:10.1152/ajplung.00162.2015

23. Li H, Yuan X, Tang J, Zhang Y. Lipopolysaccharide disrupts the directional persistence of alveolar myofibroblast migration through EGF receptor. Am J Physiol Lung Cell Mol Physiol (2012) 302(6):L569-79. doi:10.1152/ ajplung.00217.2011

24. Bock C, Reither S, Mikeska T, Paulsen M, Walter J, Lengauer T. BiQ Analyzer: visualization and quality control for DNA methylation data from bisulfite sequencing. Bioinformatics (2005) 21(21):4067-8. doi:10.1093/ bioinformatics/bti652

25. Yu X, Wang W, Wei Z, Ouyang F, Huang L, Wang X, et al. Vitamin D status and related factors in newborns in Shanghai, China. Nutrients (2014) 6(12):5600-10. doi:10.3390/nu6125600

26. Tao M, Shao H, Gu J, Zhen Z. Vitamin D status of pregnant women in Shanghai, China. J Mater Fetal Neonatal Med (2012) 25(3):237-9. doi:10.31 09/14767058.2011.569613

27. Kramer BW, Kallapur S, Newnham J, Jobe AH. Prenatal inflammation and lung development. Semin Fetal Neonatal Med (2009) 14(1):2-7. doi:10.1016/j. siny.2008.08.011

28. Walsh MC, Szefler S, Davis J, Allen M, Van Marter L, Abman S, et al. Summary proceedings from the bronchopulmonary dysplasia group. Pediatrics (2006) 117(3 Pt 2):S52-6. doi:10.1542/peds.2005-0620I

29. Joung KE, Burris HH, Van Marter LJ, McElrath TF, Michael Z, Tabatabai P, et al. Vitamin D and bronchopulmonary dysplasia in preterm infants. J Perinatol (2016) 36(10):878-82. doi:10.1038/jp.2016.115

30. Lykkedegn S, Sorensen GL, Beck-Nielsen SS, Christesen HT. The impact of vitamin D on fetal and neonatal lung maturation. A systematic review. Am J Physiol Lung Cell Mol Physiol (2015) 308(7):L587-602. doi:10.1152/ ajplung.00117.2014
31. Jobe AH. Animal models, learning lessons to prevent and treat neonatal chronic lung disease. Front Med (2015) 2:49. doi:10.3389/fmed.2015.00049

32. Litonjua AA, Weiss ST. Is vitamin D deficiency to blame for the asthma epidemic? J Allergy Clin Immunol (2007) 120(5):1031-5. doi:10.1016/j. jaci.2007.08.028

33. LaCasse CJ, Janikashvili N, Larmonier CB, Alizadeh D, Hanke N, Kartchner J, et al. Th-1 lymphocytes induce dendritic cell tumor killing activity by an IFN-gamma-dependent mechanism. J Immunol (2011) 187(12):6310-7. doi:10.4049/jimmunol.1101812

34. Miller NM, Wang J, Tan Y, Dittel BN. Anti-inflammatory mechanisms of IFN- $\gamma$ studied in experimental autoimmune encephalomyelitis reveal neutrophils as a potential target in multiple sclerosis. Front Neurosci (2015) 9:287. doi:10.3389/fnins.2015.00287

35. Maslova E, Hansen S, Thorne-Lyman AL, Jensen CB, Strom M, Cohen A, et al. Predicted vitamin D status in mid-pregnancy and child allergic disease. Pediatr Allergy Immunol (2014) 25(7):706-13. doi:10.1111/pai.12295

36. Nguyen M, Guillozo H, Garabedian M, Balsan S. Lung as a possible additional target organ for vitamin D during fetal life in the rat. Biol Neonate (1987) 52(4):232-40. doi:10.1159/000242714

37. Yang CY, Leung PS, Adamopoulos IE, Gershwin ME. The implication of vitamin D and autoimmunity: a comprehensive review. Clin Rev Allergy Immunol (2013) 45(2):217-26. doi:10.1007/s12016-013-8361-3

38. Gruzieva O, Merid SK, Melen E. An update on epigenetics and childhood respiratory diseases. Paediatr Respir Rev (2014) 15(4):348-54. doi:10.1016/j. prrv.2014.07.003

39. Jo P, Jung K, Grade M, Conradi LC, Wolff HA, Kitz J, et al. CpG island methylator phenotype infers a poor disease-free survival in locally advanced rectal cancer. Surgery (2012) 151(4):564-70. doi:10.1016/j.surg.2011.08.013

40. Zhang XQ, Lv CJ, Liu XY, Hao D, Qin J, Tian HH, et al. Genomewide analysis of DNA methylation in rat lungs with lipopolysaccharide-induced acute lung injury. Mol Med Rep (2013) 7(5):1417-24. doi:10.3892/mmr.2013.1405

41. Koroglu OA, Onay H, Cakmak B, Bilgin B, Yalaz M, Tunc S, et al. Association of vitamin D receptor gene polymorphisms and bronchopulmonary dysplasia. Pediatr Res (2014) 76(2):171-6. doi:10.1038/pr.2014.63

42. Makishima M, González-Mateo GT, Fernández-Míllara V, Bellón T, Liappas G, Ruiz-Ortega M, et al. Paricalcitol reduces peritoneal fibrosis in mice through the activation of regulatory T cells and reduction in IL-17 production. PLoS One (2014) 9(10):e108477. doi:10.1371/journal.pone.0108477

Conflict of Interest Statement: The authors declare that the research was conducted in the absence of any commercial or financial relationships that could be construed as a potential conflict of interest.

The reviewer LD and handling editor declared their shared affiliation.

Copyright (c) $2018 \mathrm{Liu}$, Chen, Li, Huang and Zhang. This is an open-access article distributed under the terms of the Creative Commons Attribution License (CC BY). The use, distribution or reproduction in other forums is permitted, provided the original author(s) or licensor are credited and that the original publication in this journal is cited, in accordance with accepted academic practice. No use, distribution or reproduction is permitted which does not comply with these terms. 